\title{
EL ALQUIMISTA
}

\author{
THE ALCHEMIST
}

\section{LUIS BORTESI LONGHI ${ }^{1}$ \\ Docente Asociado de la Facultad de Ciencias Contables, UNMSM}

(Recepción: Agosto de 2009 / Conformidad: Setiembre de 2009)

\section{RESUMEN}

En el mundo financiero se comprueban instrumentos y procedimientos cada vez más sofisticados que resultan a veces incomprensibles por su impresionante nivel de abstracción.

Si ya el dinero en sí es un invento que implica un paso hacia la desmaterialización, en la economía contemporánea la desmaterialización llega a extremos límite y se convierte a la finanzas en una pura y simple «anotación en cuenta».

El presente artículo se refiere a las diversas potestades y maneras que tienen los gobiernos de crear «riqueza» artificialmente y está motivado en especial por la reciente crisis financiera internacional y la reacción adoptada particularmente por Estados Unidos.

Palabras clave: Riqueza artificial crisis financiera internacional, el alquimista.

\begin{abstract}
In the financial world are tested tools and more sophisticated procedures that are sometimes incomprehensible for its impressive level of abstraction.

If you have the money itself is an invention that involves a step toward dematerialization, in the contemporary economy dematerialization reaches extreme limits and the finance becomes a pure and simple «book-entry form».

This article refers to the various powers and ways for governments to create «wealth» artificially and is motivated in particular by the recent international financial crisis and the reaction particularly taken by the United States.
\end{abstract}

Key words: Artificial ealth, international financial crisi , the alchemist

1 Doctor en Ciencias Económicas y Magister en Economía. Docente de la Unidad de Postgrado de la Facultad de Ciencias Contables, UNMSM. E-mail: luisbortesil@hotmail.com 


\section{INTRODUCCIÓN}

Bufón: «ilos mágicos billetes! No los entiendo muy bien»

«Cinco mil coronas han llegado a mis manos!»

Mirad, vale esto dinero?

Mefistofeles: «Tienes para lo que ambicionan garganta y tripas»

Bufón: «y puedo comprar tierras, casa y ganado?»

Mefistofeles: «iPor supuesto!» Puja, que bien sabes

hacerlo

Bufón: «y palacio con bosque y caza y río lleno

de pesca?»

«Esta noche me meceré en mis tierras»

FAUSTO

JohanN Wolfgang Von Goethe Parte II-Acto I (en el palacio imperial)

El bufón es el «loco» de palacio único personaje autorizado a decirle la verdad al rey sin faltar al reglamento cortesano.

Goethe (1749-1832) fue un portentoso fenómeno humano que se interesó también por la alquimia. Fue admirado y condecorado por Napoleón Bonaparte, pese a la distancia entre ambos bandos.

En 1775 Carlos Augusto, heredero del ducado de Sajonia, invitó a Goethe a trabajar en Weimar, su capital. Allíllegó a ocupar el cargo de ministro consejero y Ministro de Finanzas donde desarrolló un efica programa de inversiones y reformas y un formidable despliegue de apoyo a la cultura, con la ardiente participación de la duquesa, que impulsaron decididamente el progreso de Sajonia.

Entre la polifacética experiencia intelectual del longevo poeta, se incluye la investigación de la alquimia aunque no se sabe hasta qué grado penetró en sus misterios. Pero algunos tratadistas han enfocado el análisis de la obra magna de Goethe, «FAUSTO» descubriendo su mensaje alquimista en diversos niveles: en el plano del alma, del amor, de la inmortalidad y de la economía, tal como se grafica en el epígrafe a manera de introducción de este artículo.

«Alquimia», vocablo de evidente origen árabe, fue llamada la ciencia que al parecer floreció en Alejandría del Egipto tardío y basaba sus principios (como toda ciencia tradicional) en las leyes de la analogía. La Doctrina Hermética parte del principio de que el universo, el macrocosmos, y el hombre, se corresponden mutuamente y lo que hay en uno debe hallarse también, de algún modo, en el otro.
Los soportes para la meditación y la obra alquímica son el Azufre, el Mercurio y la Sal y sus planetas correspondientes, así como la comprensión del proceso de expansión y contracción (solve et coagula) tal como son los impulsos del corazón y de la respiración.

La transformación del plomo en oro significa pasar del estado pesado, caótico, bruto, al estado puro de luz solidificada: el sol y su símbolo, el oro.

Pero, y esto es lo más importante, la obra alquímica no consiste en una vulgar intención de obtener oro con afán de lucro, sino que el proceso se debe convertir en la base de una transposición espiritual, cual es la del Arte Regia y Superior que supone la «técnica» de la transformación del alma.

En este sentido, la práctica que se utiliza en la alquimia no difiere, en sustancia, de las otras que buscan la trascendencia del estado de conciencia con el propósito de alcanzar niveles supra racionales como lo es, por ejemplo, el yoga.

Independientemente de los tres elementos que interactúan en el crisol (azufre, mercurio y sal) están presentes las formas primordiales que conforman el cuaternario: agua, tierra, aire y fuego; y su respectiva condición: líquido, sólido, gas e ígneo; o bien, húmedo, seco, frío y caliente.

La sublime manifestación de las sustancias del crisol superan el cuaternario y trascienden a una «quintaesencia» que en sánscrito se conoce como «akasha» que sugiere, en cierta manera, al «éten».

Se considera que una de las más logradas fórmulas que expresan el misterio de la alquimia está cifrada en la famosa Tabla Esmeraldina donde se sintetiza la naturaleza de la Obra.

«1.-Es verdad, ciertamente y sin duda: lo de abajo es igual a lo arriba, y lo de arriba, igual a lo de abajo, para obrar los milagros de una cosa.

2.-Así como todas las cosas proceden del Uno y de la meditación del único, también todas las cosas nacen de este Uno mediante conjugación.

3.-Su padre es el Sol, y su madre, la Luna, el viento lo llevó en su vientre y su nodriza es la Tierra.

4.-Es el padre de las maravillas del mundo entero.

5.-Su fuerza es perfecta cuando se convierte en tierra.

6.-Separa la tierra del fuego y lo fino de lo grueso, suavemente y con todo cuidado.

7.-Sube de la tierra al cielo y de allí vuelve a la tierra, para recibir la fuerza de lo de arriba y de lo de abajo. Así poseerás la luz de todo el mundo, y las tinieblas se alejarán de ti.

8.-Esta es la fuerza de todas las fuerzas, pues vence a todo lo que es fino y penetra en todo los sólido. 
9.-Por tanto, el mundo pequeño esta hecho a semejanza del mundo grande.

10.-Por ello, y de este modo, se obraran aplicaciones prodigiosas.

11.-Por eso me llaman Hermes Trismegisto, pues yo poseo las tres partes de la sabiduría de todo el mundo.

12.-Terminado está lo que he dicho de la obra del Sol.»

La alquimia tradicional, de origen árabe, cayó en desprestigio porque durante el medioevo tardío se desplegó una actividad puramente mundana, es decir anti metafísica, con el propósito vulgar e inferior de fabricar el oro-metal para tener riqueza económica. Tales talleres merecieron, por parte de los sabios, el despectivo calificativo de «sopladores de carbón».

Después surgiria la hija bastarda de la Alquimia, la química, que es tan profana como la Astronomía, ciencia que se limita a los fenómenos sensibles, negando toda realidad Metafísica, con respecto a la Astrología.

$\mathrm{Si}$ aquellos artesanos trabajaban la producción de oro partir del plomo, el sistema financiero moderno ha logrado producir «riqueza» a partir de la NADA. Y es en esta dirección precisamente en la que se orienta lo que trata el presente escrito.

Un precursor simbólico de la catástrofe que acarrea la alquimia vulgar está magistralmente descrito en el mito griego del rey Midas. Bello, joven, fuerte, el soberano de Frigia promueve el culto a una divinidad de rango medio, y muy poco conocido: Dioniso.

En recompensa, éste le confiere un regalo, un don, fuere cual fuere. Midas le pide que todo lo que él tenga en su contacto físico se convierta en oro. Y, naturalmente, ocurrió una desgracia, porque el pan se transformaba en oro y el oro... no es comestible. Arrastrándose, desfalleciente, Midas le ruega al dios que lo exonere de $\tan$ terrible sortilegio.

Cuando, siguiendo las instrucciones de Dioniso, midas se baña en las aguas del río Pactolo, logra su liberación y, dice la leyenda, que aún en nuestros días ese río arrastra pepitas de oro...

Difícilmente se podrá encontrar un parangón, en materia de sutileza, equivalente al invento del dinero. No se encuentra ninguna invención humana de carácter institucional que ofrezca tantas posibilidades de perversión y, paralelamente, que resulte tan necesaria y sintetice el centro del quehacer y la preocupación prioritaria del mundo entero.

Si no existiese el dinero la inmensa mayoría de los crímenes dejaría de tener razón de ser. Por eso, Martín Lutero, el herético sacerdote Agustino, siempre rígido, dijo que el dinero era el estiércol del demonio.
Pero, ¿qué es en realidad el dinero?. Con un doblón de oro en la palma de la mano la respuesta se hace fácil, mas no es así de fácil explicar qué es, por ejemplo, el «dinero electrónico», puesto que con la desmaterialización de la economía se ha llegado al límite de abstracción, al colmo de la fantasía, al borde de lo irreal.

En la actualidad se puede aseverar que el dinero es el UNICO bien sobre la tierra que no tiene absolutamente ningún valor de uso pero que encarna la inexplicable paradoja de poseer un valor de cambio, convencional, que puede llegar a ser muy alto.

Igualmente el dinero, en el mundo contemporáneo, es el único bien garantizado exclusivamente por él mismo, es decir su "garantía» proviene de la nada.

Se dice que el rey de Lidia, llamado Gige, acuñó por primera vez en la historia el elektron, una combinación de oro y plata. El evento aconteció en aquel pequeño reino del Asia Menor dentro de la órbita de la cultura griega hacia fines del siglo VIII antes de la era cristiana.

La moneda acuñada aparece en Grecia bastante tiempo después, alrededor de 630 años A.C. y se denominaba el óbolo y con el dinero apareció, fatalmente, su resultado generacional: el interés y la usura.

Juntamente con el dinero nace también su hermano gemelo, el mercado y todos los signos de los tiempos, como salidos de la caja de Pandora, afloran la filosofía, la ciencia, la economía, la polis, la democracia, el individualismo, la pobreza personal y la soledad del hombre.

En una situación de vida de la tribu la suerte era colectiva. Se hacían ritos de auspicio para propiciar las estaciones, los favores del sol, del viento y de la lluvia y los buenos tiempos o la adversidad favorecían o castigaban a toda la parentela.

Con la presencia del dinero el trabajo cambia de sentido puesto que no se trata ya de una actividad para satisfacer una necesidad inmediata sino que el esfuerzo se orienta a una ganancia pecuniaria. En esta época surge la distinción tajante entre el trabajo puramente intelectual y el trabajo manual.

Es por virtud de la invención del dinero que se polarizan extremadamente las posibilidades de riqueza y pobreza porque el dinero permite una acumulación ilimitada que jamás antes fue posible.

Posteriormente sobreviene la revolución industrial y, alrededor del dinero, aparece el capitalista burgués cuyas características principales se pueden resumir diciendo que exalta el individualismo, es activo e industrioso, racional y calculador, metódico, serio en sus deberes , juicioso y temeroso de Dios. Toda su vida está orientada sistemáticamente a la ganancia lucrativa a través del trabajo. 
El cálculo inspirado en el dinero satura completamente el sentido de la existencia humana. Benjamín Franklin (la imagen central grabada en el billete 100 dólares) es el prototipo de este modelo de vida. En su mentalidad todo está reducido al cálculo: privilegiando el trabajo, cuota para rezar, para comer, para el sueño, y tener en cuenta siempre que «el tiempo es oro»

Es lógicamente lícito inducir que si el tiempo es oro, el oro es tiempo. Y el moderno sistema financie $\mathrm{o}$, el alquimista, va a basarse en esta primera premisa para desplegar su actividad introduciendo como factor concomitante la noción de la compra del tiempo futuro sometido a un riesgo.

El sistema financiero está compuesto fundamentalmente por cuatro personas jurídicas activas: el Ministerio de Finanzas, el Banco Central, el conjunto de Bancos Privados y la Bolsa de Valores.

Dos entidades son las encargadas de la supervisión del sistema financiero: la superintendencia de la banca y la comisión de vigilancia y control de empresas y valores.

Más adelante se verá cómo es verdad que las cuatro personas jurídicas activas señaladas en el párrafo de arriba «crean» dinero y también se verá que la única columna que sostiene la entera estructura financiera reside exclusivamente en el factor confianza, es decir se basa únicamente en un comportamiento psicológico que como se comprenderá fácilmente es la mayoría de las veces ilusorio, frágil y precario.

Previamente es oportuno mencionar la existencia del Gran Alquimista que es el sistema financiero internacional presidido por los Estados Unidos de Norteamérica.

Hacia el año 1844 era Inglaterra la sede del sistema. Siguiendo la línea de la «currency school» (haciendo una traducción libre la podríamos llamar la escuela de paridad de cambio) marca una proporción fija entre el dinero circulante y la reserva áurea, en monedas acuñadas con metales finos y en lingotes (bullion). Este se llama el Sistema Gold Standard. Fue adoptado por casi todos los países avanzados y se extendió a los Estados Unidos en la década de los setenta durante el siglo diecinueve.

«Pagadero al portador», siempre en oro, rezaban los billetes bancarios. Por entonces la moneda fuerte era la libra esterlina (The Pound).

Desde el 17 de abril del año 1898 en el Perú, bajo el gobierno de don Nicolás de Piérola y Villena, comenzó la circulación de un nuevo signo monetario, la libra de oro, con las mismas características físicas que la esterlina; en el anverso estaba el busto de Manco Cápac rodeado de la siguiente inscripción:
«Verdad y Justicia. Una libra». En el reverso estaba grabado el escudo peruano circundado por la frase República Peruana.

Por aquel entonces el lema orgulloso que vibraba en los corazones y en las gargantas peruanas era « $\mathrm{ja}$ la par con Londres!».

Este periodo tuvo vigencia hasta que se desató la Primera Guerra Mundial. Para poder cubrir los colosales gastos militares los Estados ponen en circulación billetes que inundan todos los establecimientos falsificando cualquier valor real. Se decreta así el deceso del sistema Gold Standard.

Sin embargo (vaya paradoja de la historia) la Segunda Guerra Mundial abre la oportunidad a la resurrección de aquel sistema.

En efecto, durante el primer semestre del año 1944 en Washington se tenía la certeza de la victoria final e, inspirados en esa convicción, a los Estados Unidos se dispusieron a reordenar todas las esferas de la actividad del planeta, en el campo Político, Financiero y Comercial, incluyendo el transplante de la Societè Des Nations desde Ginebra a NewYork, y es así entonces que se funda la nueva United Nations impulsada con mentalidad innovadora donde la «democracia» la ejercerían exclusivamente los cinco países vencedores.

En el dominio del sistema monetario internacional, se decidió convocar un cónclave en Bretón Woods, en el Estado de New Hampshire, asamblea llevada a cabo en un apartado hotel (que aún existe) escogido este solitario paraje por razones de seguridad. Los dos personajes principales en la cita fueron el representante británico John Maynard Keynes y, naturalmente, el americano Harry Dexter White.

El nuevo orden financiero internacional se basaría en las siguientes instituciones: el International Monetary Fund (FMI) para controlar las balanzas de pago de todos los países así como las políticas fiscales. El Banco Mundial que actuaría en forma solidaria con el fondo. El GATT, (general agreement on trade and tariff) para controlar el comercio internacional y el nuevo sistema monetario bautizado como «Gold Exchange Standard» que reconoció que el dólar es convertible a oro a razón de treinta y cinco dólares por onza troy (una onza equivale a 31.1 gramos). El respaldo de esta decisión fue la declaración, por supuesto nunca comprobada, de que existía un fabuloso tesoro de oro depositado en las arcas de Fort Knox.

Todo aquello se urdía en julio del año 1944 en la conferencia de Bretón Woods, y en el acta final se escribe como encabezamiento: «For a durable Peace».... 
Esto resultó, en la práctica, en una verdadera imposición que todos los países occidentales tuvieron que aceptar en virtud de la fuerza política y militar de los Estados Unidos. Estos imprimieron una cantidad impresionante de dólares con los cuales pudieron comprar a precio de remate las propiedades de, literalmente, medio mundo. El supuesto respaldo que debería haber tenido esa hemorragia dineraria no existía, ni siquiera contabilizando todo el oro del mundo, extraído y por extraerse.

Los americanos que deberían haberse limitado, según los acuerdos, a estampar no más de 10.000 millones de dólares, en la realidad emitieron otros 80.000 .

Fue el presidente francés Charles De Gaulle, quien encabezó la iniciativa de varios países europeos en la solicitud presentada ante los Estados Unidos para convertir sus dólares a razón de treinta y cinco por onza troy. Esta necesidad respondió principalmente a la demanda por oro que exigía el cártel árabe de los países productores de petróleo.

Fue así que el «sistema» se desplomó espectacularmente en agosto 15 del año 1971 cuando en un acto celebérrimo, no precisamente por su honestidad o prestigio, el presidente Richard Nixon decretó la abolición unilateral de los acuerdos de Bretton Woods.

Los europeos inventaron el "petrodólar», una especie de moneda vinculada a la fluctuación del precio del petróleo, cuya vida fue breve y tormentosa.

En realidad el dinero está emancipado de todo valor intrínseco y la economía es cada vez más desmaterializada.

En el mundo «civilizado», si en un hotel o en un restaurante se paga con moneda corriente en vez de tarjeta de crédito, el cajero no podrá disimular la sorpresa y mirará al parroquiano como si fuera un salvaje peligroso.

La desmaterialización de la economía alcanza su límite con la incursión del dinero electrónico que ya forma parte del sistema de pagos mediante impulsos de bit y byte.

También los demás instrumentos financieros están desmaterializados. ¿Quién ha visto, por ventura, una Acción en su expresión física?

Todas las transacciones tienen carácter virtual y es digno de subrayarse el hecho de que con la moneda electrónica se fractura el último vínculo entre dinero y materia.

Paralelamente otra evidencia que es preciso recalcar es que la clave de la producción de riqueza no reside en el trabajo sino en la habilidad y la astucia para mover dinero. El dinero financiero, por otra parte, no es dinero para gastar puesto que con él no se compra nada. Solamente sirve para ganar más dinero. $\mathrm{El}$ rico no es aquel que posee grandes patrimonios organizados para la producción sino que es aquel capaz de mover inmensas sumas financiera .

Retomando el tema de El Alquimista, se puede hablar, en primer lugar, sobre la naturaleza de los Bancos.

Si un niño inteligente, fresco y despierto, le preguntara a su papá: papá, ¿qué es un banco?

Y el papá, privilegiando la síntesis, le dijera: « hijito, un banco es una organización que vende dinero a un precio mayor que el nominal. Además, debo aclararte que el dinero que el banco vende no es de su propiedad, e incluso, en gran medida, el banco vende dinero que él mismo se encarga de crear».

En éste caso, ¿el papá habría mentido? Pues no, el papá habría dicho la verdad.

Entre los siglos XVII y XVIII la economía es el centro de la vida del hombre. Y en el siglo diecinueve el dinero se mete en el centro de la economía.

La introducción del papel moneda y del dinero bancario llevó a una vertiginosa proliferación de los medios de pago. Jugando con el cálculo de las reglas de las probabilidades, la banca realiza lo que se llama el «apalancamiento», es decir multiplica, según el caso, hasta en veinte veces la base patrimonial que lo sustenta. Este apalancamiento (en inglés leverage) determina que cualesquiera fuese un banco entrado en descrédito, no podría soportar una avalancha de clientes que reclaman sus dineros, simultáneamente, un lunes a las nueve de la mañana. Sobre esto existen pruebas abundantísimas e irrefutables.

De otro lado, es curioso fijarse en una jerga admitida en el ambiente bancario. Se trata del neologismo llamado «cuasi dinero» que no es otra cosa que un formidable multiplicador de créditos a partir de proyecciones abstractas. El cuasi dinero es el monto del apalancamiento que, si bien constituye crédito, no lo es con base de liquidez al ciento por ciento.

El Alquimista tiene dos importantes cómplices que son el Banco Central y el Ministerio de Finanzas . Si bien es cierto el Banco Central tiene como misión «inflación cero», es igualmente cierto que está en condiciones de crear todo el dinero que quiera a partir de la NADA. y, de hecho, lo hace a discreción cuando, por ejemplo, decide comprar moneda extranjera, por millones, y luego quiere «esterilizar» lo que soltó...

En cuanto al Ministerio de las Finanzas, se puede decir que contribuye en «el proceso alquímico» cuando vende los famosos Bonos del Tesoro. Por lo general estos bonos son papeles que sirven para pagar deudas de refinanciación de deudas cuando se 
contrajeron otras deudas sobre deudas para pagar deudas... Pero evidentemente los bonos del tesoro, ni son ni tan «buenos», (la raiz de «bono», o «bond» es «bueno») ni provienen de ningún tesoro.

El juego bursátil, acólito del alquimista, crea expectativas y apuestas a futuro que pueden llegar a multiplicar el supuesto valor de los activos financieros, no precisamente en base a la verdadera riqueza, sino como producto de la especulación pura.

Algo debe andar muy mal en el sistema financiero moderno, porque existen preguntas que atormentarían a cualquier interlocutor sensato y que pese a ser elementales no tienen respuestas satisfactorias.

La riqueza aumenta pero la población se empobrece cada vez más.

La riqueza aumenta pero la desocupación masiva configura una de las peores injusticias que soporta la humanidad.

La percepción de inseguridad y de precariedad es la fuente de angustia generalizada en todas las sociedades urbanas.

El motivo está alrededor de la perversión cultural que supone poner al dinero, irracionalmente, como fin y no como medi .

¿Cómo es posible que en la práctica el fin de nuestras actividades consista en la codicia de crear dinero en lugar de crear bienestar?

El sistema económico deja paso a la artificialidad de las reglas financieras a las cuales se encuentra totalmente sometido y subordinado. Las consecuencias son que vivimos en el espejismo y la falsedad.

Gracias a esta falacia hemos podido anticipar y extender los consumos de una manera que no se podrá soportar indefinidamente. Hemos vampirizado e hipotecado el futuro como si fuera algo real, como si fuera algo concreto, como si figurase en nuestro balance como un bien inmueble de nuestra propiedad.

Es éste el perverso poder mágico de El Alquimista.

\section{CONCLUSIÓN}

En la crisis financiera internacional que vivimos y que fue originada por una avalancha inorgánica de préstamos hipotecarios en los Estados Unidos, papeles de segunda categoría (subprime), se colocaron instrumentos de deuda masivamente a personas carentes de capacidad de pago. Se estructuraron paquetes que fueron vendidos y revendidos sucesivamente arrastrando con este procedimiento inmoral a bancos de gran tamaño, compañías financieras, aseguradoras que fueron literalmente contagiadas a nivel planetario.

Para salir de la crisis el alquimista mayor, Estados Unidos, imprimió (se podría decir falsificó) primero 880 mil millones de dólares que no resultaron suficientes y el gobierno tuvo que pedir otros 220 mil millones para tratar de zanjar la situación. La consecuencia de todo esto es el cuestionamiento del sistema neoliberal, particularmente desde el punto de vista financier, el deterioro agravado del dólar y el desprestigio del país más poderoso del mundo, todavía, en virtud de su enorme prepotencia militar.

Pero lo más probable es que se concluya un tema que ya se está discutiendo: la necesidad de un nuevo orden monetario internacional así como la renovación de los organismos mundiales encargados del sistema financiero y acuerdos vinculantes relativos a medidas preventivas de control de riesgos.

\section{REFERENCIAS BIBLIOGRÀFICAS:}

1. GARCÍA MARZÁ. Domingo; "La Empresa Socialmente Responsable. Ética y Empresa"; 2003.

2. GONZÁLEZ FABRE, Raúl; "Ética Y Economía"; 2005.

3. KUMAR SEN, Amartya; (Alianza Editorial); "Sobre Ética y Economía"; 2001.

4. STIGLITZ JOSEPH "Making globalization work” Penguin Books; 2006.

5. STIGLITZ JOSEPH and LINDA BILMES "The three trillion dollar war" W.W. Norton; 2008.

6. SUZUKI DAVID, "The behemoth that wouldn't stop growing", (www.davidsuzuki.org/about_us.).

7. VELASQUEZ, Manuel G. "Ética En Los Negocios. Conceptos y Casos"; (2006). 